\title{
Course Syllabus and Assessment Instrument Development System: An Integrated Approach
}

\author{
Naseer Ahmed, Anwar M. A., Abdurahem Mohammed Al Ameen \\ Al Ghurair University, Dubai Academic City, Dubai, United Arab Emirates
}

\begin{abstract}
Properly developed course syllabus and carefully designed assessment instruments certainly play a remarkable role in streamlining and enhancing student learning process. The instructors can easily design and develop such a syllabus as well as associated assessment instruments, if they are provided with an integrated knowledge-based system that supports a mechanism for selecting and developing various components of course syllabus such as course learning outcomes (CLOs), course topics/learning activities, assessment instrument scheme as well as permit them to develop appropriate and balanced assessment instruments that are particularly designed to assess the intended CLOs specified in the course syllabus. In this paper, we propose a knowledge-based system for developing appropriate and effective course syllabus and effective formative and summative course assessment instruments based on the principles of Bloom's taxonomy. A prototype system is developed using MS Access 2007. This system facilitates instructors in writing appropriate course learning outcomes, preparing course content and delivery schedule and also allows them to develop various assessment instruments incorporating six levels of Bloom's Taxonomy cognitive skill domains.
\end{abstract}

\section{Introduction}

There has been ever growing awareness for systematic and thoughtful assessment of student learning across the higher education sector. Since its introduction in 1956, Bloom's taxonomy has been increasingly used to develop outcome-based curricula and course syllabi. It also offers a useful guide for mapping out instructor's assessment plans and provides a structured way to design and develop the appropriate assessment instruments and tools for a particular course. The importance of creating and developing outcome-based course syllabus and assessment instruments is briefly discussed in the following sections.

\section{Outcome-based course syllabus}

A course syllabus for any course can be regarded as a contract between instructor and student that is formulated well before the beginning of a particular course and that remains valid from the first day of class until the final course grade is assigned [1]. To enrich and enhance student learning experience throughout the duration of the course offering, a course syllabus must be designed and developed keeping in view the outstanding learning and pedagogical practices. Our institutional experience shows that many instructors face difficulty in writing effective syllabus especially when it comes to incorporating the principles of Bloom's taxonomy of cognitive domains. Therefore, it would be highly beneficial, if the instructors are provided with a knowledge-based system that will present a step-bystep guidance and assistance for developing all major components of a course syllabus incorporating Bloom's taxonomy.

It is important to note that specific requirements for developing a syllabus might vary from course to course or instructor to instructor, however, every course syllabus generally must contain some standard components which are essential to make it a meaningful document for an effective and significant student learning process. These standard components include course title, course code, credits, prerequisite requirements, instructor information, course description, course learning outcomes (CLOs), textbook(s), main topics of the course, learning activities and delivery schedule, instructional resources, course assessment instrument scheme and procedures, and other course specific or institutional policies. The inclusion of these components in a syllabus is of utmost importance for students to know exactly the nature of the course both in terms of what they can expect from the course and what is required by the students throughout a particular course.

Most of the information required to be included in a syllabus is generally available (in print and/or electronic format) to the instructor through university catalogue, student handbook, approved curricula or related departmental and institutional curriculum documents. However, the most important components of a syllabus are CLO statements, content delivery and schedule, learning activities and assessment scheme or procedures. These components provide important roadmap of the entire learning process for students, instructors and other stakeholders. The CLO statements of a course depict cognitive abilities and skills that students must acquire and effectively demonstrate once that particular course is concluded. These statements 
should not only be realistic and meaningful but must also be measureable [2]. This condition requires the use of some measurable action verbs to compose CLO statements to stipulate that these learning outcomes will yield a terminal, observable and quantifiable performance; the ultimate objective of a course.

The learning outcomes also have a direct impact on learning activities and assessments. These components are closely linked to one another and must have a constructive alignment amongst each other [3]. To achieve such an alignment, it is imperative to ensure that each of these three components (outcomes, activities, assessments) has the same action verb to identify what students will be able to do during a particular course. For example, if a learning outcome is that students will be able to analyze a situation or set of facts, the same verb "analyze" should be apparent in the learning activities and in the assessments that are aligned with that outcome [4]. This further reinforces the importance of using a proper framework for structuring learning outcomes of a particular course while developing the course syllabus for that particular course. One of the traditional but widely used frameworks for structuring learning outcome statements is Bloom's taxonomy of educational objectives [5].

\subsection{Outcome-based assessment instruments}

A number of definitions of assessment are available in the literature [6-9]. However, the most comprehensive definition is provided by Tom Angleo [8] which is being reproduced below.

"Assessment is an ongoing process aimed at understanding and improving student learning. It involves making our expectations explicit and public; setting appropriate criteria and standards for learning quality; systematically gathering, analyzing, and interpreting evidence to determine how well performance matches those expectations and standards; and using the resulting information to document, explain, and improve performance."

In the context of academic programs of study, student assessment activities are conducted at various levels, viz., institutional, program, and the course. The activities at all these levels must be closely linked and synchronized to one another. At the program level, the program learning outcomes are clearly indentified to indicate what the students would be able to know or do upon completing a particular program of studies. The program learning outcomes are essentially derived from the institution's mission and goals/outcomes. To measure the effectiveness of each program learning outcome, a well-conceived assessment plan is developed with clear benchmarks and criteria upon which the quality of student learning is measured. At the course level, each course must contribute towards the assessment of at least one program learning outcome that in turn supports the institutional goals/outcomes. For every course, appropriate CLOs must be developed to explicitly state the knowledge, skills and attitudes this course aims to develop within each student at the completion of this course. In this paper we restrict our discussion to the course level assessment only.

Assessment of student learning begins in the classroom while the course is being delivered by the individual instructors. This is one of the key activity which helps in understanding and improving not only the student learning and development but also the teaching effectiveness in a particular course. Therefore, each and every course in a given program is carefully developed by stating clear learning outcomes or expectations, defining suitable teaching and learning activities and more importantly selecting appropriate assessment methods that would help instructors in assessing success of the course in terms of predefined expectations. In other words, the assessment instruments administered in a course must be designed to ascertain whether the learning outcomes or expectations are being achieved by the students at the completion of that particular course.

As discussed earlier, a syllabus must be provided to the students as it allows the concerned parties (institution, instructor and student) to form realistic expectations [10]. The assessment within a particular course includes both formative (assessment for learning) and summative (assessment of learning) [11]. The formative assessment is generally designed to probe the progress of students during the course whereas the summative assessment is used to learn how well the student has met the learning outcomes or expectations at the end of the course. To achieve the desired results from any of the assessment instrument, it is highly imperative that each instrument is designed while keeping in mind the CLOs and the learning activities to teach that particular course. All of these three components (outcomes, activities, and assessments) must be properly aligned to one another according to the constructive alignment framework suggested by Biggs [3]. This alignment requires that these three components have the same action verb to identify what students will be able to know or do during a particular course.

The Bloom framework [5] provides six levels of performance for Bloom's cognitive domains i.e., knowledge, comprehension, application, analysis, synthesis, and evaluation and thus offers a useful guide to map out the course content, related learning and assessment activities to the desired cognitive skill levels ranging from lower (remembering, understanding) to higher levels of thinking (applying, 
analyzing, evaluating, and creating). These domains are arranged in ascending order of cognitive complexity starting from knowledge (lowest level) to evaluation (highest level). This framework allows instructors to design and develop perfectly aligned learning outcomes, learning activities and assessment instruments in a manner that entire learning experience of students is more productive and enhanced.
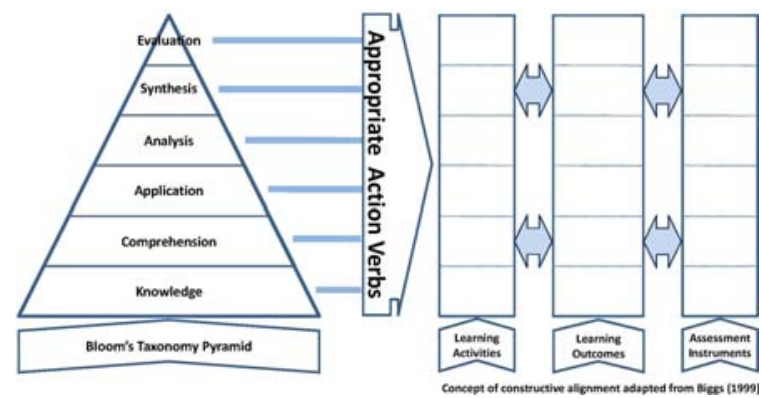

Figure 1. Constructive alignment and bloom's taxonomy

While delivering the content of a course and conducting related teaching and learning activities in the class, one of the most important steps is the development of assessment instruments (i.e., assignments, quizzes, class tests and exams, essays/term papers, presentations, projects/laboratory work, portfolios etc.) in accordance with the assessment scheme envisioned in the course syllabus. The assessment instruments must exhibit a curricular validity in the sense that they have a valid relationship between the course content and its stated learning outcomes [12-14]. Figure 1 provides an integrated view of the constructive alignment framework while maintaining an appropriate corresponding linkage with various cognitive skill domains of Bloom's taxonomy. Each component (outcomes, activities, and assessments) must not only be aligned to one another but must also correspond to an appropriate cognitive skill domain. For example, for an application level learning outcome, students must be taught and assessed using appropriate learning activities and assessment instrument which are designed to teach and test the application-level skills, for example, apply, demonstrate, compute, sketch, solve, etc. The use of appropriate Bloom's action verbs in phrasing learning outcomes, learning activities and assessment questions in a course can help instructors to plan and implement the constructive alignment.

As discussed earlier, the course assessment must be appropriate to the course content (or learning and teaching activities) and must be designed to assess the stated CLOs. The quality of the assessment instruments can greatly be enhanced if the instructors are provided with an assessment instrument development tool that is capable of storing, retrieving and presenting the important information necessary for writing or composing an assessment instrument. The information that might be very useful for the instructor at the time of writing an assessment instrument includes (i) CLOs that need to be assessed in a particular assessment instrument as per the assessment scheme envisioned in the course syllabus, (ii) course content and learning activities associated with these CLOs, (iii) the amount of time spent in delivering topics or conducting learning activities in achieving these CLOs, (iv) Bloom's action verbs associated with the cognitive skill domain of the CLOs being assessed in the instrument. Almost every book published these days is accompanied by some kind of application to generate assessment instruments (for example view reference [15]) that instructors may use to develop assessment instrument. Some home-developed tools designed for similar purposes are also available [16]. However, none of these keeps a proper record of what has been taught in the class and which CLO is linked to which topic(s) or learning activity of the course.

This paper is an attempt to propose an integrated knowledge-based system that would allow instructors to develop their course syllabi that includes structuring CLOs, write course contents, plan and develop delivery schedule and learning activities as well as develop assessment scheme while incorporating key principles of Bloom's framework. This system will be quite helpful for instructors in preparing a balanced and quality assessment instrument in which all assessment questions are carefully mapped to the CLOs in order to achieve a proper alignment of teaching and student learning experiences with syllabus outcomes. A plenty of material and information is already available both in the literature and on the Internet that includes a comprehensive database of action verbs associated with six Bloom's cognitive domains $[17,18]$. The proposed system uses a database of these action verbs that are useful in defining a particular level of achievement that ultimately helps in designing desired learning activities as well as in designing an assessment scheme and assessment instruments for testing the cognitive development or skill acquired by students after completing these activities during a particular course. The system also ensures that each course syllabus is developed which conforms to the institutional guidelines and standards that are generally embedded in a standardized syllabus template designed by the institutional committees. The system not only stores the valuable course information such as CLOs, assessment scheme, course topics/learning activities associated with each CLO, the time devoted to each topic/learning activity, and a proper record of previous assessment instruments administered in the 
class but also makes all this information available to the instructor to assist him in developing various assessment instruments for that particular course. The system described in this paper is an extension of our previous work [19] which was designed to develop an appropriate and effective course syllabus based on the principles of Bloom's taxonomy. We are confident that proper implementations of this system will not only minimize the efforts and time spent by instructors for developing course syllabi and related assessment instruments but will also ensure that these items adhere to the principles of Bloom's taxonomy and related assessment theories.

Database model is discussed in section 2 whereas the system architecture and its details are described in section 3. In section 4, discussion and conclusions of the proposed system are presented.

\section{Database Logical Model}

A physical or logical data model is a representation of a domain's data, organized in terms of tables or entities and relationships which provide insight of the structure of a database. The data modeling is an important phase of database design and development. It provides a means to analyze business requirements so as to standardize organizational vocabulary, enforce business rules, and ensure adequate data quality. Since data has become a vital corporate resource, good data models can make a significant contribution to an organization's future success.

The physical database model shows all table structures, including column name, column data type, column constraints, primary key, foreign key, and relationships between tables. The physical data model of the database used in our proposed system is presented in Figure 2. There are ten main tables whose names starts with prefix tbl and four tables with prefix rel are used to implement relationship amongst these tables. The tables with rel prefix have been used to relate two tables which have many-tomany relationships. For example, relCoursePolicy table indicates a relationship between tblCourse and tblPolicy. One policy might be related to many courses or many policies might be related to one course. This type of relationship is a many-to-many relationship and must be broken into two one-tomany relationships. The rel tables also provide a place for storing information which may not be meaningful if stored in any of the participating tables. For example, in relQuestionAssessment table there is a field QuestionMarks which keeps record of marks for each question in each assessment.

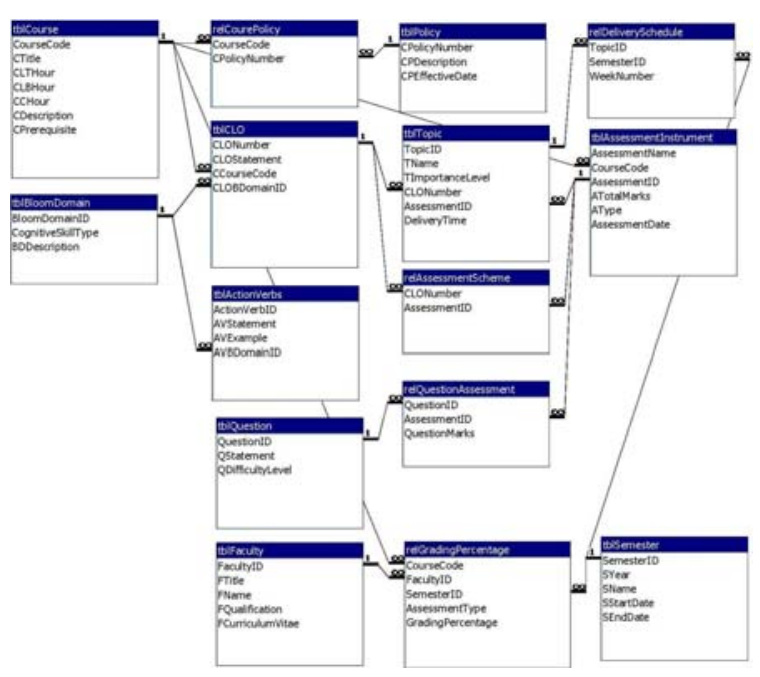

Figure 2. Database model for course syllabus and assessment instrument development system

\section{System architecture}

The system architecture of the proposed knowledge-based system is shown in Figure 3. The proposed system consists of three layers; database layer, graphical user interface (GUI) layer, system's module layer. The database layer has three data repositories namely Bloom's taxonomy repository, course/program repository, and policy repository.

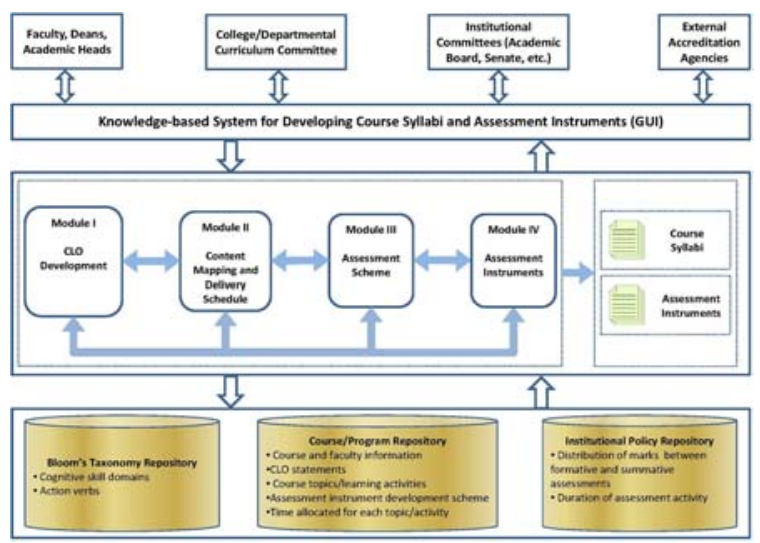

\section{Figure 3. Knowledge-based syllabus development system architecture}

The Bloom's taxonomy repository stores information relating to the Bloom's taxonomy cognitive skill domains and associated actions verbs. Course/program repository stores full details of courses i.e. course code, course title, description, faculty information, CLO statements, course topics/learning activities, assessment scheme and the time allocated for each learning activity in the class. The policy repository stores information relating to institutional policies and regulations designed to 
govern and monitor the quality of delivery of courses and academic programs. The data stored in this repository includes attendance policy, academic integrity policy, assessment and grading policies.

The GUI layer allows various users i.e. instructor, academic heads, curriculum committees, etc. to interact with the knowledge-based system to perform desired tasks. The system module layer allows users to perform specific tasks through four modules that are listed below.

a) CLO development module

b) Content mapping and delivery schedule module, and

c) Assessment scheme development module

d) Assessment instrument development module

The details of these modules are discussed in the following sub-sections.

\subsection{CLO development module}

This module is designed to facilitate instructors to structure CLOs of a particular course through a window as shown in Figure 4.

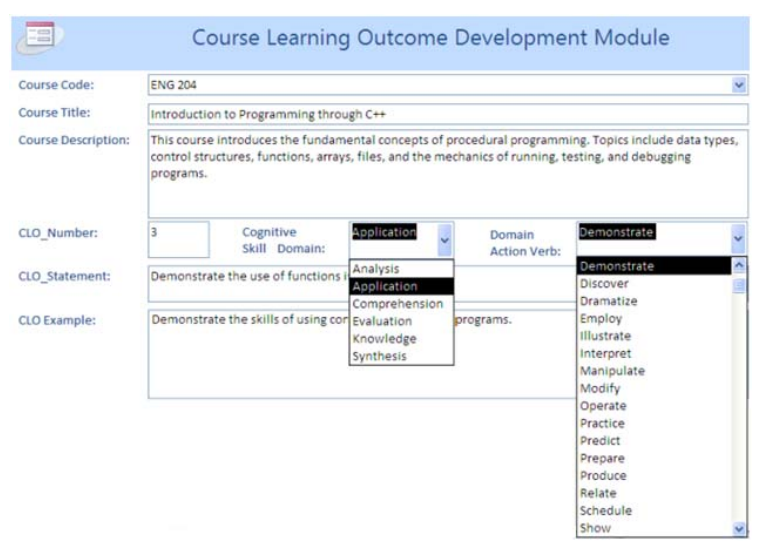

Figure 4. CLO development module

The instructor selects a desired course code from the course list in the "Course Code" combo box which in turn triggers the system to retrieve the course related information in the course title and course description textboxes. The system extracts this information from the course/program repository within the database layer of the system. The instructor then enters the CLO number in the CLO field and selects the appropriate cognitive skill domain of the Bloom's taxonomy from the "Cognitive Skill Domain” combo box which displays all of the six domains. The respective action verbs list appears in the "Domain Action Verb" combo box and the instructor selects the relevant action verb in order to write a learning outcome statement. The system also displays an example of CLO statement associated with the selected cognitive skill domain in the CLO example textbox. The instructor then writes the desired CLO statement based on the information presented in this window. This CLO statement is then stored in the database which is subsequently used in other modules of the system. This approach will certainly help instructors to avoid writing outcome statements containing passive verbs (for example, "be exposed to," "be familiar with," "understand" and "develop an appreciation of," etc.) which are not observable and quantifiable. The availability of such information in one window helps instructors in writing observable, measurable and quantifiable learning outcome statements.

\subsection{Content mapping and delivery schedule module}

This module is used to enter and associate course topics and learning activities, time for its delivery, and week number to a particular CLO. The relevant window for using this particular module is shown in Figure 5.

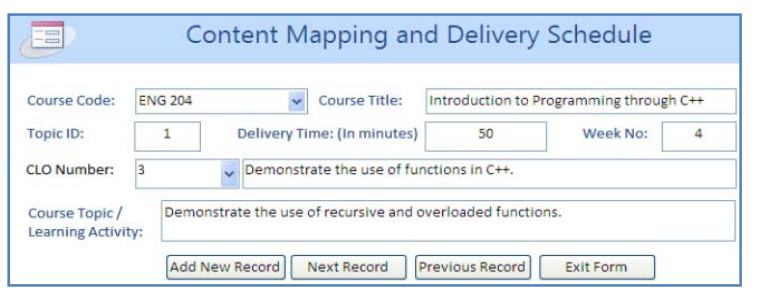

\section{Figure 5. Content mapping and delivery} schedule module

The instructor selects course code from the "Course Code" combo box that displays the course title in the "Course Title" textbox. Then s/he selects the appropriate CLO number from the "CLO Number" combo box that displays the CLO statement next to the selected CLO number. These CLO statements have already been stored in the system database after the instructor has developed all CLOs for this course using the CLO development module discussed in section 3.1. The instructor enters the topic/learning activity that s/he plans to teach relating to the selected CLO. The instructor also enters the time needed to cover this topic/activity and the week number in which this topic/activity will be carried out in the appropriate textboxes of this form. For example, in Figure 5, instructor selects ENG 204 and its title "Introduction to Programming through $\mathrm{C}++$ " is displayed in the textbox next to it. Then instructor selects CLO number 3 from the list "CLO Number" combo box and the CLO statement "Demonstrate the use of functions in $\mathrm{C}++$ " is displayed. Then s/he writes the topics/activity i.e. "Demonstrate the use of recursive and overloaded functions" in the "Course Topic/Learning Activity" textbox. Each record entered in this module is stored in the system. As 
shown, different buttons are provided to enter a new record or to navigate through the existing records are provided in the module.

\subsection{Assessment scheme development module}

The window for this module is shown in Figure 6. Through this window the instructor develops an assessment scheme for a course that will be used to develop formative and summative assessment instruments while teaching that course.

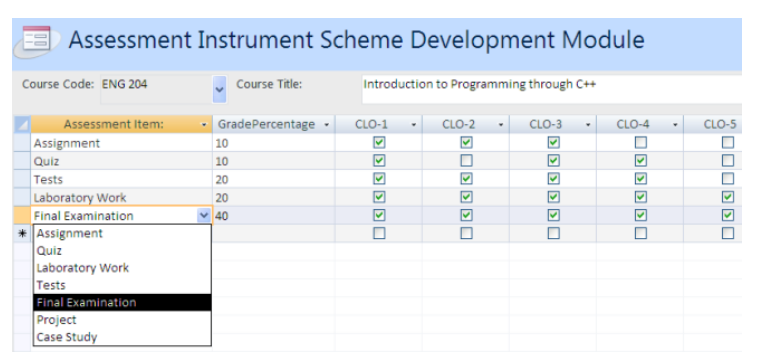

\section{Figure 6. Assessment scheme development module}

The instructor selects the course code in the combo box and course related information such as course title, course description etc are displayed in appropriated textboxes. Then s/he selects the appropriate formative or summative assessment item (for example, assignment, quiz, test, project, case study etc,) from the "Assessment Item” combo box and enters the appropriate percentage in the "Grading Percentage" field and then checks the relevant CLO box which s/he plan to test using the selected assessment item. This scheme along with the related data is stored in the system database layer. The scheme itself is quite useful at the time of developing various assessment instruments at the time of offering this particular course. The system also allows instructors to add stored information or data such as course credits, course pre-requisite(s), faculty information, office hours, text or reference book(s), program/institutional policies and to generate the syllabus in a format prescribed by the institution.

\subsection{Assessment instrument development module}

This module has two sub-modules (i) information display sub-module, (ii) assessment instrument development sub-module. The information display sub-module displays all relevant information which is necessary for the instructor to develop the type of the assessment instrument selected. The assessment instrument display sub-module facilitates instructors to develop and compose various questions of the desired assessment instrument. The instructor interacts with the system through the interface windows of the assessment instrument development sub-module. Once instructor selects the type of the assessment that he intends to develop from the assessment scheme of a particular course, the assessment instrument development module retrieves the data from the database repositories and displays all necessary information which is helpful for the instructor to develop that particular assessment instrument. A snapshot of the assessment instrument development window is shown in Figure 7. In this case, the instructor intends to develop a "Test" (the type of instrument he/she intends to develop) for the course having a code "ENG 204".

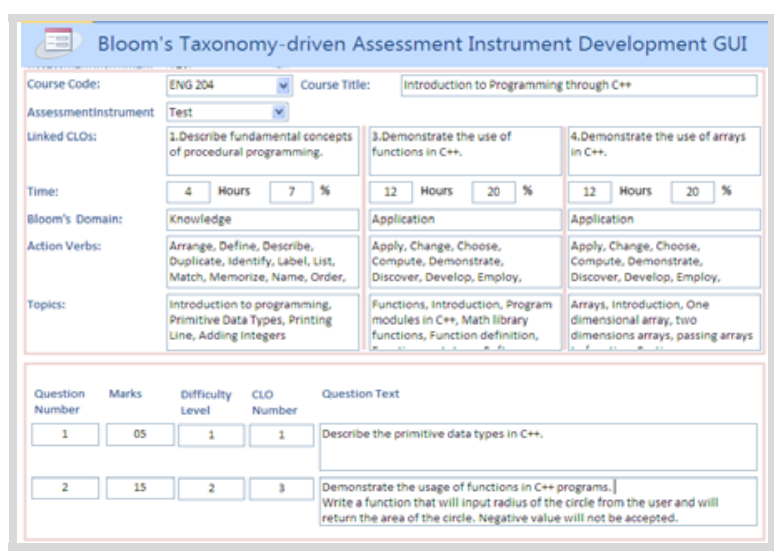

\section{Figure 7. Snapshot of assessment instrument development window}

The details of the information retrieved from the database and displayed in the window of Figure 7 are given below.

a) "Course Title" textbox shows the title of the course "Introduction to Programming through C++"

b) The type of assessment instrument that instructor intends to develop "Test"

c) Full statements of the CLOs (i.e., CLO1, CLO3, and CLO4) associated with the selected instrument (Test)

d) Time devoted for topics associated with these CLOs is displayed below each CLO

e) The cognitive skill domains, associated action verbs, and course topics (learning activities) relating to each of these three CLOs are also shown in the relevant textboxes

The lower box of the module is used by the instructor to enter the appropriate information about each question composed by the instructor. For example, to assess CLO1 the instructor has composed question 1 which carries 5 marks. The text of the question entered is "Describe primitive data types in $\mathrm{C}++$ " which is in align with the relevant CLO of the course. The system also allows the instructor to enter question number, marks allocated 
for each question, difficulty level, and CLO number in the appropriate boxes. In the case of question 1, the assigned difficulty level is 1 . Similarly the instructor composes all questions that he/she intend to include in this "Test". The entire data entered by the instructor is stored in the system database which can later be used to generate the printed version of the assessment instrument "Test" in a standardized format prescribed by the institution.

\section{Discussion and conclusions}

To develop balanced and constructively aligned assessment instruments that assess various learning outcomes of a course, it is vital that the instructors are provided with the support and functionality of course syllabus and assessment instrument development tool that would facilitate them in preparing course syllabus as well as composing appropriate questions keeping in view the amount of time spent on various learning activities associated with a particular CLO or cognitive domain. This approach would not only prevent the use of passive action verbs but also ensure that the assessment instruments are not unfairly skewed towards any one of the cognitive domain. The proposed system is an effort to provide instructors with all necessary information at the time of developing the syllabus and the assessment instruments to ensure its quality and alignment with the Blooms taxonomy cognitive skill domains as envisioned in the course syllabus.

We have proposed and successfully implemented a prototype of a knowledge-based system that assists instructors in preparing a course syllabus that not only contains all essential components of a typical syllabus but also is prepared in accordance with the sound pedagogical principles especially Bloom's taxonomy of educational objectives in a standardized format prescribed by the institution. The relevant information made available through this system allows instructors to phrase each question for assessing associated learning outcome. The system proposed here has been found to be useful for instructors in developing and generating Blooms taxonomy compliant formative and summative assessment instruments. This system is capable of providing the necessary and relevant information to the instructor in one window as and when they intend to develop either a course syllabus or any assessment instrument necessary to assess various CLOs of the course.

This system can also be used to maintain a question bank of quality assessment instruments with different types of questions created by different instructors. This question bank can be utilized in creating assessment instruments just by choosing the desired questions from the database. The same system can also be enhanced to generate and conduct online tests. Furthermore, the system can be designed to add features for seeking and incorporating the comments from internal or external examiners in order to improve the quality of assessment questions and assessment instruments. We also intend to implement this system as a Web-based application that will be much more efficient and effective for all instructors from their desktop personal computers. The database developed with this system can also be used to feed a CLO assessment data warehouse for storing historical curriculum and assessment data which could be used for monitoring and evaluation of all courses and academic programs offered by the institution.

\section{Acknowledgements}

The authors wish to acknowledge Al Ghurair University for its support to develop this system.

\section{References}

[1] Zucker, K.D., Baker-Schena, L., Pak, M., (2010) "The Course Syllabus: Contract, Culture, and Compass”, The Teaching Professor, Magna Publications, Madison, USA, January,

http://www.magnapubs.com/newsletter/story/4839/ June 2011).

[2] Popham, W. J., (1970) "Instructional Objectives 1960-1970”, NSPI Journal, 5-7, 16.

[3] Biggs, J., (1999) "Teaching for Quality Learning at University”, SRHE and Open University Press, Buckingham.

[4] Halverson, T., (2010) "Inspiring and Aligned Assessments of Student Learning that are Linked to the Real World",

http://ctl.byu.edu/showArchivePage.php?\&pageUID=Kzcb 6CYcQ9NX (23 June 2011).

[5] Bloom, B.S., Englehart, M.D., Furst, E.J., Hill, W.H. and Krathwohl, D.R., (1956) Taxonomy of Educational Objectives: Handbook 1: Cognitive Domain, Longman, New York.

[6] "Assessment of Learning - The National Teaching and Learning Forum” (2011)

http://www.ntlf.com/html/lib/faq/al-aahe.htm (23 June 2011).

[7] Erwin, T.D., (1991) Assessing Student Learning and Development, San Francisco: Jossey-Bass Publishers.

[8] Angelo, T. (1995) Reassessing (and Defining) Assessment. The AAHE Bulletin, 48(2).

[9] Palomba CA, Banta TW. (1999) Assessment essentials: Planning, implementing, and improving assessment in higher education. Jossey-Bass, San Francisco, CA. 
[10] Gutbrod, H. "The Syllabus as Contract and Strategy All You Really Need to Know" http://www.gtu.ge/qa/instruction/SyllabusasStrategyandCo ntract.pdf (28 June 2011).

[11] http://amec.glp.net/c/document_library/get_file?p_l_id=78 1847\&folderId $=754745 \&$ name $=$ DLFE-20967.pdf (28 June 2011).

[12] Anastasi, A., (1988) Psychological Testing, London: Prentice Hall.

[13] Aiken, L., R., (1994) Psychological Testing and Assessment, London: Allyn and Bacon.

[14] Kline, P., (1986) A handbook of test construction. London: Methuen.

[15]

http://wpslive.pearsoncmg.com/cmg_instructor_testgen_1/ 136/34890/8931911.cw/index.html (28 June 2011).

[16] Klefstad, B., Maribu, G., Horgen, S. A., Hjeltnes, T., (2010) Learning Outcomes and a Taxonomy as a Starting Point for creating digital Multiple-choice Tests. Seminar.net - International journal of media, technology and lifelong learning, Vol. 6, Issue 3.

[17] Bloom’s Taxonomy Action Verbs.

http://www.clemson.edu/assessment/assessmentpractic es/referencematerials/documents/Blooms\%20Taxonomy\% 20Action\%20Verbs.pdf (23 June 2011).

[18] Verbs to Use in Creating Educational Objectives (Based on Bloom's Taxonomy).

http://www.educationoasis.com/curriculum/LP/LP_PDF\% 20Word/blooms_tax_verbs.pdf (23 June 2011).

[19] Ahmed, N., Anwar, M.A., Al Ameen, M. A., (2011) Knowledge-Based System for Developing Bloom's Taxonomy-Driven Syllabus and Assessment Instrument Scheme, Proceedings of Canada International Conference on Education (CICE-2011), Toronto, Canada. 